\title{
Skill Formation among Vocational Rehabilitation Clients - Public Policy vs Private Incentives
}

\author{
by
}

\author{
Arild Aakvik* and Egil Kjerstad $^{* *}$
}

\begin{abstract}
In this paper we analyse individual vocational rehabilitation clients' decisions to enter active training or not. Although the Government pays the direct costs of training, the composition of the total costs of training may be decisive for individual choices. Based on labour market theory, we relate background characteristics of the clients to monetary opportunity costs and non-monetary costs of training, arguing that training choices are a consequence of differences in costs of training. We use a ten percent sample of participants in educational programs, work related training and non-participants who entered the Norwegian vocational rehabilitation sector in the period from 1989 to 1993 , a total of 6653 persons. We find that the background characteristics of persons investing in educational training differ along several dimensions compared both to persons attending work related training and to clients not participating in training at all.
\end{abstract}

Keywords: public policy, private incentives, costs of training, educational training, work related training, vocational rehabilitation

\footnotetext{
* Department of Economics, University of Bergen.

*** Foundation for Research in Economics and Business Administration (SNF) and Programme for Health Economics in Bergen (HEB).

Many thanks to Jan Erik Askildsen, Kjell Vaage and Andrew Jones for comments on earlier drafts. Thanks also to seminar participants at SNF. The Norwegian Social Data Service (NSD) in Bergen provided the data. All the data are gathered from sources at The Directorate of Labor, The Social Insurance Organization and Statistics Norway. Both researchers thank the Ministry of Labor and the Research Council of Norway for financial support. None of the mentioned institutions are in any circumstances responsible for the analysis or for the conclusions drawn from it.
} 


\section{INTRODUCTION}

Conditions like ill health and/or mismatch of individuals' skills and the requirements in the labour market can for some lead to a permanent withdrawal from the labour market. For instance, people with ill health - making them unable to perform their traditional craft or to perform according to employers' expectations - may end up as long term unemployed and finally, with a disability pension. However, unemployed may still have a chance to find employment by acquiring new skills in accordance with their health condition and the demand for skilled workers in the labour market. Governmental interventions in the areas of post-schooling employment schemes and training programs may be means of achieving this. Such governmental interventions are permanent fixtures of most OECD countries and the interventions normally have two basic goals: to reduce unemployment and poverty by increasing skills of certain groups of the population. Both objectives require that the schemes or programs increase the probability of employment and/or increase the earnings of the participants above what they would otherwise achieve.

An almost generic Governmental view is that the main purpose of offering educational and work related training programs to partly disabled or hard to employ workers is to enhance the participants' human capital and productive skills, increase individual employment prospects and, in turn, reduce transition to disability pension. However, from a client's point of view participation or non-participation in a training program may be the result of a more complex decision making process influenced by intrinsic, and, for the Government (and researcher), unobservable characteristics of the individual client. ${ }^{1}$ Although there are observable costs, such as training fees, other cost components, such as disutility of effort, are not observable (directly at least). Thus, public policy in the area of manpower training confronts private incentives partly driven by factors not observable by policy makers, program administrators or researchers.

\footnotetext{
${ }^{1}$ The caseworker's opinion of a client's need of training may have an impact on the choice made by a client. Furthermore, a client may be rationed in the sense that the most preferred training program is not
} 
There is a huge literature devoted to estimating the effect of training programs (e.g. Ashenfelter (1978), Bassi (1984) and Heckman, Hotz and Dabos (1987)) and to analysing the particular econometric issues involved when estimating such effects (e.g. Heckman and Robb (1985), Heckman and Hotz (1989), Moffitt (1991) and Heckman and Smith (1996)). For a discussion of a Norwegian VR program see Aakvik (2001). The topic of sample selection and the deleterious effects on the properties of conventional estimators such as least squares has been at the core of much of the recent work. The basic problem is that selection bias arises when a non-random selection process determines participation in training programs. Researchers do not observe all explanatory variables influencing program participation and outcome.

Selection bias is of course not only an econometric issue. The ambition of Governmental programs is to 'hit the right people', an ambition usually stated quite explicitly. The selection bias may be a 'real life problem' if the Government allocates scarce resources mainly to program participants who without a training program would do as well in the labour market as with such training. Thus, when evaluating the impact of training programs on earnings or on the probability of getting employed one should take into account the fact that the impact might be correlated with variables determining participation in the first place.

The importance of unobservable characteristics of a client becomes particularly evident when noting that skill formation can be acquired in a variety of situations with different levels of training costs for an individual. Generally, participants in training programs incur three types of costs and the composition of cost components can affect the training decisions taken by the individuals. Firstly, participants usually have to pay a tuition fee to participate in a training program. Sometimes the employer or a third party, like local or central Government, pays this direct cost. Secondly, it is often assumed that participation in a training program gives rise to non-monetary costs (NMC) or disutility

available. We have neither information allowing us to measure caseworkers' impact on the choices made by clients nor the degree of rationing. 
of training born by the individual. Thirdly, the clients incur monetary opportunity costs (MOC) in terms of lost income while attending training. ${ }^{2}$

It is the complex decision making process at individual level we find interesting, an issue that most often is treated implicitly in the evaluation literature. By shifting focus from estimating mean effects of training to modelling and testing an individual's decision to participate, we take one step back in the decision making process compared to much of the evaluation literature. Basically, our main aim is to study the selection process itself. We analyse whether clients participating in active training separate themselves from non-participants and whether clients participating in general and specific training programs separate themselves from each other in terms of background characteristics.

Our approach is to use the background characteristics as indicators of an individual's cost of training and thereby his or her incentives to participate. Our main hypothesis is that differences in training costs are decisive in forming the individual's incentive to participate in training or not. Heterogeneity in innate abilities of an individual and/or the particular welfare benefits the client is eligible to receive, are among the important variables that influence costs of training. Specifically, based on human capital and signalling theory, ${ }^{3}$ we relate differences in previous education and age to differences in non-monetary costs (NMC) of training. Differences in previous income and status as recipient of VR benefits give raise to differences in monetary opportunity costs (MOC) of training. Spouse's income may also give rise to differences in the cost of training.

\footnotetext{
${ }^{2}$ See for instance Elliott (1991) for a discussion of private costs of human capital investment.

${ }^{3}$ The main difference between human capital and signalling interpretations of training is that signalling models allow for attributes that are not observed by the firm to be correlated with training. According to Weiss (1995) sorting models (signalling and screening models) of education (training) can best be viewed as extensions of human capital models. Sorting models extend human capital theory models by allowing for some productivity differences that firms do not observe to be correlated with the costs or benefits of schooling. In fact, Weiss argues that sorting models subsume all the features of human capital models. However, while human capital theory is concerned with determining the return to schooling, sorting models, while allowing for learning, focus on the ways in which schooling serves as either a signal or filter for productivity differences that firms cannot reward directly.
} 
The data consist of a random 10 percent sample of persons who entered the Norwegian vocational rehabilitation sector in the period from 1989 to 1993, a total of 6653 persons. ${ }^{4}$ We find that the background characteristics of persons investing in educational training differ along several dimensions compared both to persons in work related training and to VR clients not participating in any training. Firstly, participants in educational training programs have background characteristics that indicate comparatively low NMC (disutility of effort) of participating in training programs. Secondly, they also have background characteristics that indicate comparatively low MOC. Persons attending work related training have background characteristics indicating both higher NMC and higher MOC compared to participants in educational training. Non-participants have background characteristics indicating relatively high NMC of training compared to both of the other groups of clients.

The paper is organised as follows. In section 2 we present some important features of the Norwegian VR sector. In section 3 we model an individual's decision-making process, make a closer distinction between different cost components of training and discuss the incentives to train. The data used in the analysis are presented in section 4 along with descriptive statistics. Our main findings are presented in section 5 while conclusions and policy implications are drawn in section 6.

\section{INSTITUTIONAL FEATURES OF THE VR SECTOR}

Public concern about the level of investment in human capital among the unemployed and those outside the labour market is quite evident in OECD (1998). The report gives a description of the importance of OECD Governments attributing to the strategic role of human capital investments. Based on an international adult literacy survey, the report

\footnotetext{
${ }^{4}$ VR clients participating in educational training are usually integrated into ordinary classes in the public school system, or attend classroom training aimed specifically at unemployed people. The purpose of these programs is to enhance an individual's human capital in a way that is compatible with demands from a relatively large number of different types of jobs, i.e. general training. Work related training usually includes one or more of the following: employment in the public sector, wage subsidies, physical rehabilitation, sheltered work, and vocational training in specific occupational skills sometimes leading up to a vocational certificate. Work related training programs are often targeted at enhancing individual skills in a more narrow range of jobs, i.e. specific training.
} 
concludes that job-related training by employed people constitutes a high proportion of all adult education and training activity. On average, people who are not employed are less likely to participate in job-related training. Those outside the labour market are more likely than employed people to participate in education and training unrelated to work. Also, participation in continuing training is strongly related to educational attainment. Those with less initial human capital appear to lack incentives or opportunities to acquire more later in life, creating the risk of exclusion. This is true for all countries in the study. ${ }^{5}$ It is notable that the differences in participation rates between countries are as great as differences between well and poorly educated groups within countries. See also Chapman (1993) for a comprehensive discussion of different aspects of training: theory, empirical evidence and policy issues.

In Norway, concern about the gap in education between partly disabled and nondisabled workers has resulted in comprehensive use of educational programs of a general character. Education in the ordinary school system is the most widely used VR program aimed at partly disabled workers in Norway. Also, the VR sector offers different work related training programs to enhance specific skills. ${ }^{6}$

The Norwegian vocational rehabilitation sector has expanded rapidly since the national social insurance act was passed in 1966. The number of participants in training programs has stabilised during the 1990s. There are around 35,000 persons in different VR programs each day, which is around 1.5 percent of the labour force in Norway. The expansion has neither been guided by a firm knowledge of the overall economic impact of the training programs, nor by knowledge of who selects the different training

\footnotetext{
${ }^{5}$ Norway is not among the countries covered by the survey. Our study will be a contribution to analyzing whether the selection mechanism found elsewhere in Europe is replicated for Norway. See also OECD (1996) for a review of problems associated with assessing and certifying occupational skills in vocational education and training.

${ }^{6}$ There is a gap of general and specific skills between partly disabled and both unemployed and employed non-disabled workers in Norway. Less than 70 percent of the vocational rehabilitation (VR) clients in Norway have high school or more, while the same number is 75 percent for ordinary unemployed. In the labor force around 85 percent have high school or more. Furthermore, Hansen (1996) finds that VR clients have less work experience and are less likely to hold a vocational certificate compared to nondisabled workers.

${ }^{7}$ Note that job search assistance is not considered training. Such assistance is open for everyone at local labor market agencies at no direct cost to the user.
} 
programs. Given the amount of public funds channelled into these areas of public policy and the ultimate goals of the spending, this may seem at odds with the present focus on accountability in the public sector.

The VR sector offers income maintenance payments (VR benefits) and training programs for individuals with reduced productivity in the labour market due to medical conditions. The decision to offer VR benefits is made by the local Social Security Office, usually after a recommendation by a medical doctor. ${ }^{8}$ The rehabilitation benefit is usually two-thirds of the gross income from the previous year subject to maximum and minimum benefit restrictions. Health status is the legal eligibility criterion for VR benefit, but labour market prospects and social integration may also implicitly be taken into account by the local Social Security Office or the medical doctor. There is no maximum number of weeks a client may receive vocational rehabilitation benefit but normally periods do not exceed 3-4 years.

While receiving VR benefit some people return to their old job or apply for a disability pension without entering the training sector. The worst cases in terms of medical diagnoses are usually granted a disability pension. Individuals who are not granted a disability pension or by their own effort return to a job, are referred to the local Employment Office where they can apply for participation in a training program. All schooling and labour market training is free - no fees are paid by the participants - and extra expenses, such as commuting, are covered by the Social Security Office. Participants without VR benefits usually rely on social assistance. Also, a smaller group is accepted for disability pensions prior to going into a training program, but these persons are not 100 percent disabled, and are thus at least able to take part-time jobs.

The process at the local Employment office starts with a conversation between a VR caseworker and the client. The consultant asks about the interests and potential

\footnotetext{
${ }^{8}$ Some institutional changes have been made in VR responsibilities in Norway. As from 1994, the labour market authorities decide on both rehabilitation benefit payments and program participation. These changes do not apply for our data.
} 
occupations, and the severity of medical conditions. The candidates for program participation supply information to the program administrator about personal preferences, motivation, ability, etc. The caseworker and the client usually decide on a rehabilitation plan. The caseworker guides the client if necessary but the interests of the client is always of main focus for the caseworker. Available training slots in areas where the applicant has shown interest may affect the final result of the selection process into a training program. The client may also decide not to participate in training.

There may be a time lag between the creation of a rehabilitation plan and the start of new training programs. During this period individuals may choose to drop out due to lack of motivation or acceptance of a disability pension. It may also be the case that some individuals receive and accept a job offer prior to the start of a training program and thus drop out. We do not directly observe who is offered a training slot but for some reason does not attend training. We only observe if a person attends training or not. If a person attends training we observe in the data the specific type of training they take.

\section{THE ECONOMETRIC MODEL}

We assume that VR clients are bounded rational, i.e. they cannot possibly foresee all the things that might matter for the decision to participate or not. Given that they do not have perfect foresight, clients have to make decisions to participate in training or not based on less than perfect information. While the effects on income from training choices are influenced by a range of exogenous factors (e.g. the future conditions in the labour market, how well others do in the courses etc.), costs of training are to be born nearer in time and are basically intrinsic to the individual. Thus, it is more difficult for an individual client to sort choices according to expected training effects on income than to sort according to cost levels. Clients are myopic.

Ex ante, i.e. before a client has made the choice, a client's utility of a particular training choice can be represented by the utility function $U_{j i}=I_{j i}-C_{j i} . I_{j i}$ is expected income, i.e. income after having participated in a training program or, as the case may be, from 
not participating in a training program at all. $C_{j i}$ is a vector representing training costs for individual $i$ choosing alternative $j$. Training costs are zero if the individual does not participate. Expected income is based on a probability distribution of finding work and knowledge of the distribution of the wage level(s) in jobs foreseen as being available to an individual ex ante. We assume that clients do not act on the differences in expected income but make their choices based on a ranking of costs associated with the different options available. Important for formulating the econometric model to be tested here is that we cannot observe a client's expected income level but we do observe indicators of the costs associated with training. We return to this shortly.

The difference in utility between state $j$ and state $k$ then becomes

$U_{j i}-U_{k i}=C_{k i}-C_{j i}$

Let $U_{j i}$ be individual $i$ 's utility from choosing alternative $y_{i}=1$ and $U_{0 i}$ be individual $i$ 's utility from choosing alternative $y_{i}=0$. We have that ${ }^{9}$

$$
P_{i}=\operatorname{Pr}\left(y_{i}=1\right)=\operatorname{Pr}\left(U_{1 i}>U_{0 i}\right)
$$

An individual's utility from the alternatives available to him/her has both a deterministic and a stochastic component. Using the case of two alternatives (participation, nonparticipation) as an example,

$$
\begin{aligned}
& U_{1 i}=U_{1 i}^{\circ}+\varepsilon_{1 i} \\
& U_{0 i}=U_{0 i}^{\circ}+\varepsilon_{0 i}
\end{aligned}
$$

\footnotetext{
${ }^{9}$ We model the decision making process as a utility maximizing process and base our model on McFadden (1973, 1976, 1978) and Domencich and McFadden (1975). McFadden's provision of a discrete utility theory has come to serve as a theoretical basis for discrete-choice models, as we employ here.
} 
where $U_{1 i}^{\circ}$ and $U_{0 i}^{\circ}$ are deterministic components and $\varepsilon_{1 i}$ and $\varepsilon_{0 i}$ are stochastic for participation and non-participation respectively.

Further specification of $U_{j i}^{\circ}$ is necessary. Let us initially divide the covariates into two groups. Let $W_{j i}$ include variables that characterise the choices in question and let $Z_{i}$ include variables that characterise the individual. We then have

$$
\begin{aligned}
& U_{1 i}^{\circ}=W_{1 i}^{\prime} \delta+Z_{i}^{\prime} \gamma_{1} \\
& U_{0 i}^{\circ}=W_{0 i}^{\prime} \delta+Z_{i}^{\prime} \gamma_{0}
\end{aligned}
$$

We can now write the $i$ th individual's probability of choosing alternative $y_{i}=1$ as a function of the net benefit of choosing participation versus non/participation:

(2) $\quad \operatorname{Pr}\left(y_{i}=1\right)=\operatorname{Pr}\left(U_{1 i}>U_{0 i}\right)=\operatorname{Pr}\left(\varepsilon_{0 i}-\varepsilon_{1 i}<U_{1 i}^{\circ}-U_{0 i}^{\circ}\right)$

Let $U_{1 i}^{\circ}-U_{0 i}^{\circ}=\left(W_{1 i}^{\prime}-W_{0 i}^{\prime}\right) \delta+Z_{i}^{\prime}\left(\gamma_{1}-\gamma_{0}\right)=X_{i}^{\prime} \beta$, where $X_{i}^{\prime}=\left[\left(W_{1 i}-W_{0 i}\right)^{\prime}, Z_{i}^{\prime}\right]$ and $\beta=\left[\begin{array}{l}\delta \\ \gamma_{1}-\gamma_{0}\end{array}\right]$. We can now write

(3) $\operatorname{Pr}\left(y_{i}=1\right)=\operatorname{Pr}\left(U_{1 i}>U_{0 i}\right)=\operatorname{Pr}\left(\varepsilon_{0 i}-\varepsilon_{1 i}<X_{i}^{\prime} \beta\right)=\operatorname{Pr}\left(\varepsilon_{i}^{\circ}<X_{i}^{\prime} \beta\right)$

or

(4) $\quad \operatorname{Pr}\left(y_{i}=1\right)=F\left(X_{i}^{\prime} \beta\right)$

where $F\left(X_{i}^{\prime} \beta\right)$ is the cumulative distribution of $\varepsilon_{i}^{\circ}$ evaluated at $X_{i}^{\prime} \beta$. McFadden (1973) has shown that if each $\varepsilon_{k i}(k=0,1)$ is independent and identical type I extreme value distributed, then the distribution of the difference $\varepsilon_{0 i}-\varepsilon_{1 i}=\varepsilon_{i}^{\circ}$ will be logistic, and the choice probabilities can be expressed by the multinomial logit. 
According to the multinomial logit model, individual $i$ will choose alternative $j$ among $J$ alternatives with probability (normalising by setting $\gamma_{0}=0$ )

$$
P_{j i}=\operatorname{Pr}\left(y_{i}=j\right)=\frac{e^{Z_{i}^{\prime} \gamma_{j}}}{1+\sum_{k=1}^{J} e^{Z_{i}^{\prime} \gamma_{k}}}, j=1, \ldots, \mathrm{J}
$$

We estimate and report the marginal effects specifically and they are given by the expression (for variable $Z_{i k}$ ):

(6) $\frac{\partial P_{j i}}{\partial Z_{i k}}=P_{j i}\left(\gamma_{j}-\sum_{k=1}^{J} P_{j i} \gamma_{j}\right)$

Turning to the more specific issues of this study, note that a VR client faces three choices: non-participation, educational training programs and work related training programs. The aim is to develop the reduced form estimation model linking, as briefly discussed above, background characteristics of the individual and training costs. We then go on linking the cost components to the probabilities of entering the three different states of 'non-participation', 'educational training' or 'work related training'.

In our reduced form maximum likelihood estimation, it is the background characteristics of the individuals that are used as explanatory variables, not the cost components. The cost components are not observable for the researcher, and measurements would under any circumstances be difficult to perform. Still, we assume that it is possible to make ordinal rankings within each cost component. We do this by stating the sign of partial derivatives of the cost functions, i.e. the direction of change in costs to changes in background characteristics. These effects are then used to state the expected sign of the probabilities of entering the different states as response to changes in the background characteristics, i.e. the expected sign of the marginal effects given by equation (6). 
The Government pays the direct costs of training ${ }^{10}$ but a client participating in training incurs other types of costs, too. In particular, there are two other basic cost components that may matter for the choices that the individuals are making: the non-monetary costs of training $\left(C_{N}\right)$ and the monetary opportunity costs of training $\left(C_{M}\right)$. Human capital investment theory and signalling theory inspired the division between non-monetary and monetary costs. The division allows a closer study of the driving forces behind the choices made by clients since we allow the composition and 'size' of the cost components to vary among clients.

Let total VR costs be represented by the cost function $C=f\left(\mathrm{C}_{N}, C_{M}\right)$. The non-monetary costs of training (NMC) can be thought of as disutility or psychological costs. These are costs experienced by all individuals participating in training but the cost varies depending on how difficult one finds learning to be. Here NMC is represented by the function

$C_{N}=g[\mathrm{EDU}, \mathrm{AGE}]$

Both education and age are commonly used as variables explaining differences in nonmonetary costs of training and the signs of the partial derivatives are in line with assumptions made in signalling theory. The lower the former education level is and the higher is the age, the higher is the level of anguish and anxiety associated with participation.

According to job-market signalling theory, ${ }^{11}$ training is correlated with differences among workers that were present before training choices were made. An important unobservable ability correlated with training is the individual's capability of adapting to new requirements at the work place. Firms may make inferences about productivity

\footnotetext{
${ }^{10}$ In the Norwegian VR system clients can make their choices under a regime of no direct financial constraints i.e. the tuition fee is paid for by the Government. Direct training costs are therefore less relevant here.

11 Spence's $(1973,1974)$ analysis rests on the assumption that persons of low-ability find signalling through training more costly than do high-ability persons. More precisely, the marginal non-monetary cost
} 
differences from training choices, and the clients respond to this inference process by choosing different levels of training or different courses. One of the main hypotheses in signalling theory is that persons with low non-monetary costs of training or low disutility of effort are inclined to signal high productive ability by choosing or selfselecting to participate in training. The argument rests on a negative correlation between productive ability and size of the non-monetary costs of training, i.e. the higher the productive ability the lower the disutility of effort and vice versa.

Thus, here we assume that a client who has a relatively high educational level before entering VR is assumed to have a comparatively low disutility of education due to the fact that he or she has already completed educational programs in the past. In contrast, the older one gets the more costly it is to participate in terms of disutility.

On the other hand, in the standard human capital model training is treated as an investment decision ${ }^{12}$ where the costs of training also consist of the monetary opportunity costs. Monetary opportunity costs take the form of foregone market opportunities. Time devoted to investment in human capital precludes the possibility of devoting that time to other market or non-market activities. Here, the monetary opportunity costs (MOC) of both types of training - work related or educational - is given by

$C_{M}=h[\mathrm{INCOME}$, SPOUSEINC, VRBEN $]$

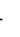

We assume that the individuals still perceive former income as a benchmark of their worth in the labour market. Thus, foregone market opportunities or monetary opportunity costs increases with higher former income level. On the other hand, we assume that the costs of training decrease as spousal income increases, i.e. the household subsidises the training costs for the individual. In other words, married or

or disutility) of education and work specific training is higher for low-ability than for high-ability persons for every level of training (Gibbons (1992)). 
cohabiting persons participating in training can partly live on their partner's income while undergoing training. An agreement can be made between partners that allows the trainee to use more of the household's income while in training or that the household agrees to reduce the consumption level in the training period. In the latter case, the reduction in consumption implicitly represents a cost. We assume that higher spousal income indicates less need to reduce consumption compared to a person with a lower spouse income. Thus, the higher spouse income, the higher is the potential drive towards training. Finally, in Norway clients may receive VR benefit (dummy variable in the regression) while undergoing training. We assume that the opportunity costs decrease if the client is a recipient of VR benefits. ${ }^{13}$

The 'priors' on the likely estimates of participation in either of the programs are given by the following partial derivatives (non-participation is given by opposite signs)

$$
\partial \operatorname{Prob}\left(\mathrm{y}_{\mathrm{i}}=1\right) / \partial C_{M}(.)<0 \text { and } \partial \operatorname{Prob}\left(\mathrm{y}_{\mathrm{i}}=1\right) / \partial C_{N}<0
$$

or in terms of marginal effects (equation (6)):

$$
\begin{aligned}
& \frac{\partial P_{1 i}}{\partial E D U_{i}}>0, \frac{\partial P_{1 i}}{\partial A G E_{i}}<0 \\
& \frac{\partial P_{1 i}}{\partial I N C O M E_{i}}<0, \frac{\partial P_{1 i}}{\partial S P O U S E I N C_{i}}>0 \text { and } \frac{\partial P_{1 i}}{\partial V R B E N_{i}}>0
\end{aligned}
$$

To sum up, our research strategy is not to estimate directly the different cost components' impact on the probability of participating in training or not $^{14}$ since direct measurement of cost is difficult to achieve. Rather we use indicators and let them enter a

\footnotetext{
${ }^{12}$ See Becker $(1962,1964)$. Acemoglu and Pischke (1998) and Barron, Berger and Black (1999) are two recent contributions in the 'Becker tradition'. Also see Elliott (1991) for a text book presentation of human capital theory.

${ }^{13}$ It is possible to receive different types of financial support while participating in training but VR benefits (based on former income) represents normally the highest level of support available. For some work related training programs, in particular training at so called Labor Market Enterprises, it is possible to receive wages instead of VR benefits but that happens only later in the training process, i.e. at least six months after first enrolling in active training.

${ }^{14}$ In the case of participation: the probabilities of choosing general or specific training.
} 
reduced form equation. In the reduced form estimation we allow the effects of changes in the background variables to influence the probability of participation directly, i.e. we estimate the marginal effects of changes in the variables on the probability of entering the different states. ${ }^{15}$

If participation or non-participation is completely random, there is no reason to expect results as predicted by the model. We hypothesise that the process contains systematic components and expect to find the following results:

1. Other things equal, younger and more educated clients are more likely to participate in active training programs, since they have comparatively low NMC. Vice versa for older and less educated clients.

2. Other things equal, clients with comparatively low previous income, high spouse income and being recipients of VR benefits are more likely to participate in active training, since they have comparatively low MOC. Vice versa for clients with comparatively high previous income, low spouse income and non-recipients of VR benefits.

3. Clients participating in active training differ systematically in terms of background characteristics and the composition of cost components, compared to nonparticipants.

4. Other things equal, clients with comparatively low NMC are more likely to participate in educational training programs than in work related training.

Point 3 is our main hypothesis and builds on points 1 and 2. Point 4 requires more discussion since it does not follow directly from (8) and (9).

Why should participants in educational training differ from participants in work related training? Spence's $(1973,1974)$ work on job-market signalling builds on the assumption that less productive or less able individuals have higher disutilty of educational training

${ }^{15}$ See Table 1 in the appendix for an overview of the total set of variables used in the empirical analysis. 
compared to more productive individuals. Thus, other things equal, using education as a signal of productive ability is more costly for the less productive. This implies that those clients with relatively high disutility of effort, other things equal (in particular equal MOC), are discouraged from participating in educational training programs. Obviously, discouraged clients have two other options. One of the options is to participate in work related training. Work related training is a more direct way of communicating information about productive ability compared to educational training. The individuals reveal information about their abilities since they are typically trained within a firm where their productivity is observed as opposed to indirect revelation (or signalling) through participation in educational programs. Loh (1994) analyses employment probation as a screening mechanism ${ }^{16}$ and finds that probation induces self-selection. Those who accept jobs with probationary employment tend to be more efficient workers and less likely to quit than those who take jobs without probation. Building on Loh, work related training could function as a screening mechanism to discourage the least qualified VR clients from participating in work related training. And since signalling through educational training is also more costly for these clients, they will be more likely not to participate in active training at all.

Still, we cannot a priori rule out that clients with the comparatively lowest NMC, i.e. the clients with lowest disutility of effort and according to Spence the more able ones, may pool with other types of clients in work related training. After all, they have the least to fear from being directly observed at the work place. Pooling of types is also possible in the educational training programs given that the less productive clients may have incentives to 'hide' as more productive clients, a point also discussed by Spence.

Lastly, as Lang (1994) points out, the distinguishing characteristic of a sorting model is that knowing an individual's education provides employers with information about that

\footnotetext{
${ }^{16}$ Loh (1994) terms probation a sorting mechanism. We prefer to use sorting as a common term for both screening and signalling. Screening is the case where the uninformed party or the principal, designs and offers a contract to the agent before the agent takes any action. Signalling is the case where the agent chooses his/her action before the principal offers a contact (see e.g. Hillier (1997)).
} 
individual's productivity which would be unknown otherwise. In human-capital models, education is not informative, because employers observe productivity directly. Thus, the models are distinguished by the role of education in conveying the individual's private information about his productivity. However, in both models units of human capital will be generated in the same way from inputs of innate ability and schooling/training.

All in all, we expect to find that the choices made follow a 'hierarchical structure':

- Individuals with comparatively low NMC will be more likely to choose educational training than work related training, other things equal.

- Individuals who are not discouraged from participating in active training but with comparatively high NMC will choose work related training, other things equal.

- Individuals who feel discouraged from participating in work related training due to possible revelation of low productive abilities and with comparatively high NMC of training will not participate in active training at all, other things equal.

Lastly, in the regressions we also use information on other background variables such as medical diagnosis, disability status, whether the client receives social benefits and whether the client was employed the year before entering the VR system.

\section{DATA}

Our data consist of people who were directed to the local labour market authorities for participation in a training program during the period 1989 to 1993 . We have relatively detailed information on socioeconomic background characteristics, labour market participation, and health status for the persons in our sample. We observe gender, age, number of children below 18 years of age, education measured in years and type of education, own income before entering the VR system, spouse's income, work experience in years, medical diagnosis, and several social security and labour market states, such as training status, vocational rehabilitation benefit and social security benefits. All of these variables change over time, except gender. 
Table 2 of the appendix shows that mean age is lowest for participants in educational training. The gender variable shows that of the 1065 participants participating in educational training most are women (approximately 52 percent). The opposite is true both for work related training and for non-participation (approximately 61 percent out of 3927 cases and 54 percent out of 1661 cases are men). Approximately 70 percent of the participants in educational training have high school or longer education, while the numbers are down to approximately 60 percent for participants in work related training and 53 percent for non-participants. The share of clients with college or university education is also higher for the educational group.

While only approximately 18 percent of the participants in educational training had received social benefits, the share is 31 percent for work related training and 24 percent for non-participants. The share of clients with disability status is 31 percent in the nonparticipation group compared to 17.5 percent in the work related and 8 percent in the educational group.

Former income level is on average higher for the educational group and the same is the case for the share of the clients receiving VR benefits. Number of years of working experience is highest for non-participants (approximately 12 years), while work related training and educational training average 10 and 8 years, respectively. The average level of spouse's income is highest for non-participants.

\section{RESULTS}

Several individual characteristics appear to have an impact on the choice of whether to participate in active rehabilitation or not, and in case of participation, in which type of program to participate. The results from the multinomial logit model, reported as marginal effects, are given in Table 3 of the appendix. We start out the discussion of the result focusing on the central variables AGE, EDU, INCOME, SPOUSEINC and VRBEN. For an explanation of these variables see Table 1. 
Table 3 shows that the clients' age appears to increase the probability of not participating in active training. For those clients that do participate, the older a client is, the more likely it is that he or she will participate in work related training and the less likely the client chooses educational training. The signs of the effects align well with the discussion in section 3. The non-monetary cost of training is assumed to increase with age, reducing the (partial) probability of participation, as the data confirm. Explaining the distinction between those that participate in educational training and work related training involves a more subtle argument. For clients participating in work related training, it must be that the non-monetary costs (or disutility of effort) of educational training is higher for every time or effort "unit' ${ }^{17}$ compared to participation in work related training. As age increases, the non-monetary costs of educational training increase relatively more compared to work related training. Thus, the probability of choosing educational training decreases with age.

Former education, the second variable influencing the non-monetary costs of training, also 'behaves' nicely but with fewer significant results compared to the age variable. Clients with only secondary school are more likely not to train compared to clients with high school education. Table 3 in the appendix show that compared to those clients with only secondary school (or less), high school education reduces the probability of nonparticipation. For clients with college education there is no significant difference compared to clients with only secondary school, though.

The results are in line with what we predicted in section 3. Higher education reduces the non-monetary costs of training and increases the probability of participation. We also find that college education reduces the probability of choosing work related training, while increasing the probability of choosing educational training programs. High school education on the other hand is not significant when it comes to explaining the choice of work related training but it is significant when explaining educational training. These

\footnotetext{
${ }^{17}$ Think of the non-monetary costs of training in terms of 'disutility units', for instance disutility per hour, day or month.
} 
results support the assumption made above that there are differences in disutility of effort between the two types of training programs. For clients that are relatively highly educated, the (marginal) non-monetary costs or disutility of educational training is lower for every time or effort 'unit' compared to work related training and vice versa for clients with secondary education or less.

Next, we turn to the variables explaining the monetary opportunity costs of training, INCOME, SPOUSEINC and VRBEN.

In section 3, we argued that being a recipient of VR benefits decreases the monetary opportunity costs of training and thereby increases the probability of taking part in active training. That prediction is confirmed in Table 3. Receiving VR benefits reduces the probability of non-participation. It is interesting to note that VR benefits also decrease the probability of taking part in work related training while increasing the probability of educational training. Adding that the size of spouse income significantly influences the probability of educational training, while having a non-significant effect on the probabilities of non-participation and work related training, gives strength to the arguments that (i) non-participants are different from participants and (ii) that participants in educational training differ from participants in work related training. The differences are most naturally interpreted as differences in NMC and MOC, as predicted in section 3 .

Former level of income does not seem to have any significant effect on nonparticipation but the higher the former income is, the less likely it is that a client chooses work related training, while it increases the probability of participation in educational training. People who invest in human capital have foregone earnings since they take training and do not work. Unemployed people (not on training) also have foregone earnings since they also are out of the labour market. However, if they are not able to get a job at all, foregone earnings is zero since foregone earnings is a combination of wages and the probability of getting that wage. An insignificant coefficient on previous income for persons not in training indicates that foregone earnings is close to zero because they 
cannot get a job. The negative sign on work related training is in accordance with the theoretical prediction in equation (9). We expect that higher previous income would reduce the probability of training, since people with the potential of earning a high income would be more eager to get back into work without training. However, it might be the case that training is necessary to maintain a high income, and that without such training the individuals would experience a drop in income. If this were the case we would expect a positive sign if the drop in income is large enough. This might be the case for persons in educational training, since the estimated coefficient is positive for this group.

Other explanatory variables also entered the regressions, and Table 3 shows that being male decreases the probability of non-participation. For those that participate, being male increases the probability of work related training while decreases the probability of education training. Turning the results around: women are more likely to choose educational training or non-participation and less likely to participate in work related training.

Being married significantly increases the probability of not participating in any program. The same is true for clients having status as (partly) disabled. As the number of years of work experience increases, the more likely it is that clients opt for non-participation. Being employed the year before registering as VR client has the opposite effect in the sense that it increases the probability of entering work related training. Recipients of social benefits have lower probability of taking part in educational training, while having children under 18 years of age increases the probability of taking part in educational training.

The dummy variables representing broad groups of diagnosis also have significant impact on some of choices made by VR clients (compared to the base category Diagnosis 0). The dummy variables for diagnosis are unordered. 
Finally, Table 3 shows that VR enrolment in 1993 significantly reduces the probability of non-participation while increasing the probability of participation.

We have tested ${ }^{18}$ both whether the vector of all the coefficients in each state are significantly different between states, and whether single coefficients are different across states. We find that the vector of coefficients is significantly different overall, i.e. the explanatory variables generally have different effects on the probability of entering the different states. Furthermore, most of the single coefficient comparisons show the same. The important non-significant test results are the AGE coefficient; the dummy variables SOCBEN and VRBEN, which have non-significant differences when comparing non-participation and work related training. Comparing the EXPER variable, we find that there is no significant difference between work related and educational training. Likewise, SPOUSEINC is significantly different only between work related and educational training, while JOB_1 is significantly different between nonparticipation and work related training only.

To sum up, we find that our results support the view that participants in educational training differ from the participants in the other two groups. Interpreting the choice made by non-participants is not self-evident but we find, as hypothesised, that nonparticipants single themselves out compared to the active clients.

\section{CONCLUDING REMARKS}

We have estimated factors affecting the probabilities of entering training using a relatively large set of background characteristics of the individuals as explanatory variables. In the theoretical discussion sub-sets of these variables are linked to the two main cost components facing VR clients: non-monetary costs of training and the monetary opportunity costs of training. Participants in educational programs have both lower non-monetary costs of training and lower monetary costs of training compared to participant in work related training. Non-participants as a group are 'poor' in terms of

\footnotetext{
${ }^{18}$ The test results are not reported in tables. Results are available from the authors upon request.
} 
decisive background characteristics. We have argued that being 'poor' increases the costs of training and lessens incentives to invest in human capital.

Our results partly fit an investment-signalling dichotomy. ${ }^{19}$ Participants in educational training have background characteristics that indicate comparatively low disutility of training as we define it. We also find that the monetary opportunity costs of training is comparatively low for this group of clients making signalling an even more attractive option. A narrow interpretation of signalling theory is that we should expect to find that clients with relatively high educational levels dominate among participants in educational training and that active clients separate themselves into the two different programs depending on factors such as former educational level and age. Another interpretation is that while participation in educational training can be interpreted as a signalling decision, participation in work related training is the same as screening.

Participants in work related training do differ from the other groups of clients in terms of relevant background characteristics and although signalling theory does not rule our pooling of types, clients taking active part in training seem to take separate actions. Thus, participating in work related training could be interpreted as an investment decision rather than a signalling decision since the client reveals private information through his/her conduct at work. This may be a debatable conclusion. A different interpretation is that clients in practice have to choose between a signalling mechanism (participation in educational training) or a screening mechanism (participation in work related training) dismissing the pure investment argument altogether. Even nonparticipation could be termed a signal, perhaps the strongest negative signal of ability seen from prospective employers' point of view.

From a governmental perspective the main aim of active training is that clients should invest in human capital and productive skills so that, in turn, transition to disability pension is reduced. As we have tried to show, an individual client may find it more

\footnotetext{
${ }^{19}$ See for instance Cohn, Kiker and Mendes De Oliveira (1987), Hungerford and Solon (1987), Belman and Heywood (1997) and Kroch and Sjoblom (1999) for empirical tests of education as human capital or signal. Based on these studies, signalling theory seems to lack decisive empirical support.
} 
rational to either stay out of training altogether or seek to separate themselves from other clients by choosing different types of training. From a policy perspective the underlying reasons that may guide an individual's decision to choose educational training versus work related could be of only minor interest as long as some kind of investment is made. On the other hand, using work related training and educational training as a sorting mechanism can be useful if clients opting for a disability pension stay out of active training anyhow and leave the VR resources available to clients with aspirations of entering the labour market again. We find results pointing in this direction since disability status significantly increases the probability of non-participation in active training. 


\section{Appendix}

Table 1. Variables used in multinomial logit regression

\begin{tabular}{ll}
\hline Variable name & Definitions \\
\hline EDU & Educational training, dummy variable. \\
NPRG & Work related training, dummy variable. \\
AGE & Non-participation, dummy variable. \\
MALE & Age, in years. \\
HIGHSCH & Dummy variable (1=male, $0=$ female). \\
COLLEGE & $\begin{array}{l}\text { Clients with at least high school education prior to VR, Dummy } \\
\text { variable. }\end{array}$ \\
CHILD18 & $\begin{array}{l}\text { Clients with at least college/university education prior to VR, } \\
\text { Dummy variable. }\end{array}$ \\
MARRIED & Clients with children less then 18 years of age, Dummy variable. \\
SOCBEN & $\begin{array}{l}\text { Dummy variable (1=married, } 0=\text { not married) } \\
\text { Dummy variable indicating if the person is receiving social benefit } \\
\text { having the value one if the person is or has received benefits in the } \\
\text { year prior to entering the vocational rehabilitation sector, and zero } \\
\text { otherwise. }\end{array}$
\end{tabular}

DISABIL

Disability pension is a dummy variable having the value one if the person is disabled (received disability pension) in the year prior to entering the vocational rehabilitation sector, and zero otherwise. The disability is less then 100 percent.

VRBEN

Dummy variable indicating if the person is receiving VR benefits.

INCOME

Income and spouse's income are measured in 100,000 Kroner (NOK). Income is measured for the year before the application and is given in 1989-kroners.

EXPER

SPOUSEINC

JOB_1

DIAGN0 - DIAGN5

YEAR89 - YEAR93
Number of years of working experience prior to VR.

\section{See INCOME}

Dummy variable having the value one if the individual is employed in the previous period, and zero otherwise. A person is employed if she has an employment spell of at least 90 days in the particular year.

Medical Diagnoses (0-5) are unordered dummy variables. Medical diagnosis 0 is used as the base category in the regressions. More information on these dummy variables is available upon request from the authors.

Year of entering VR (89-93) are dummy variables. Year89 is used as the base category in the regressions. 
Table 2. Descriptive statistics

\begin{tabular}{|c|c|c|c|c|c|}
\hline Variable & Mean & Std.Dev. & Minimum & Maximum & Cases \\
\hline \multicolumn{6}{|c|}{ EDUCATIONAL TRAINING } \\
\hline AGE & 31.7596 & 9.0649 & 16.0000 & 64.0000 & 1065 \\
\hline MALE & .4836 & .5000 & .0000 & 1.0000 & 1065 \\
\hline HIGHSCH & .7042 & .4566 & .0000 & 1.0000 & 1065 \\
\hline COLLEGE & .1052 & .3069 & .0000 & 1.0000 & 1065 \\
\hline CHILD18 & .3718 & .4835 & .0000 & 1.0000 & 1065 \\
\hline MARRIED & .3587 & .4798 & .0000 & 1.0000 & 1065 \\
\hline SOCBEN & .1831 & .3869 & .0000 & 1.0000 & 1065 \\
\hline DISABIL & .0779 & .2682 & .0000 & 1.0000 & 1065 \\
\hline VRBEN & .5897 & .4921 & .0000 & 1.0000 & 1065 \\
\hline INCOME & .9372 & .7790 & .0000 & 4.4690 & 1065 \\
\hline EXPER & 8.9483 & 6.8366 & .0000 & 26.0000 & 1065 \\
\hline SPOUSEINC & .6678 & 1.0788 & .0000 & 10.9000 & 1065 \\
\hline JOB_1 & .5418 & .4985 & .0000 & 1.0000 & 1065 \\
\hline DIAGN0 & .2056 & .4044 & .0000 & 1.0000 & 1065 \\
\hline DIAGN1 & .3793 & .4855 & .0000 & 1.0000 & 1065 \\
\hline DIAGN2 & .1587 & .3656 & .0000 & 1.0000 & 1065 \\
\hline DIAGN4 & .0620 & .2412 & .0000 & 1.0000 & 1065 \\
\hline DIAGN5 & .0516 & .2214 & .0000 & 1.0000 & 1065 \\
\hline DIAGN6 & .1427 & .3500 & .0000 & 1.0000 & 1065 \\
\hline YEAR89 & .2272 & .4192 & .0000 & 1.0000 & 1065 \\
\hline YEAR90 & .1972 & .3981 & .0000 & 1.0000 & 1065 \\
\hline YEAR91 & .2188 & .4136 & .0000 & 1.0000 & 1065 \\
\hline YEAR92 & .1634 & .3699 & .0000 & 1.0000 & 1065 \\
\hline YEAR93 & .1934 & .3952 & .0000 & 1.0000 & 1065 \\
\hline \multicolumn{6}{|c|}{ WORK RELATED TRAINING } \\
\hline AGE & 35.4026 & 11.4586 & 15.0000 & 69.0000 & 3927 \\
\hline MALE & .6114 & .4875 & .0000 & 1.0000 & 3927 \\
\hline HIGHSCH & .5944 & .4911 & .0000 & 1.0000 & 3927 \\
\hline COLLEGE & .0530 & .2240 & .0000 & 1.0000 & 3927 \\
\hline CHILD18 & .2832 & .4506 & .0000 & 1.0000 & 3927 \\
\hline MARRIED & .3491 & .4768 & .0000 & 1.0000 & 3927 \\
\hline SOCBEN & .3107 & .4628 & .0000 & 1.0000 & 3927 \\
\hline DISABIL & .1757 & .3806 & .0000 & 1.0000 & 3927 \\
\hline VRBEN & .4270 & .4947 & .0000 & 1.0000 & 3927 \\
\hline INCOME & .7765 & .7482 & .0000 & 4.3810 & 3927 \\
\hline EXPER & 10.3305 & 8.2056 & .0000 & 26.0000 & 3927 \\
\hline SPOUSEINC & .5477 & .9099 & .0000 & 10.5000 & 3927 \\
\hline JOB_1 & .4856 & .4999 & .0000 & 1.0000 & 3927 \\
\hline DIAGN0 & .2223 & .4159 & .0000 & 1.0000 & 3927 \\
\hline DIAGN1 & .3020 & .4592 & .0000 & 1.0000 & 3927 \\
\hline DIAGN2 & .3079 & .4617 & .0000 & 1.0000 & 3927 \\
\hline DIAGN4 & .0532 & .2245 & .0000 & 1.0000 & 3927 \\
\hline DIAGN5 & .0354 & .1848 & .0000 & 1.0000 & 3927 \\
\hline DIAGN6 & .0792 & .2701 & .0000 & 1.0000 & 3927 \\
\hline YEAR89 & .2401 & .4272 & .0000 & 1.0000 & 3927 \\
\hline YEAR90 & .2175 & .4126 & .0000 & 1.0000 & 3927 \\
\hline YEAR91 & .1956 & .3967 & .0000 & 1.0000 & 3927 \\
\hline YEAR92 & .1693 & .3751 & .0000 & 1.0000 & 3927 \\
\hline YEAR93 & .1775 & .3821 & .0000 & 1.0000 & 3927 \\
\hline
\end{tabular}




\begin{tabular}{|c|c|c|c|c|c|}
\hline \multicolumn{6}{|c|}{ NON-PARTICIPANTS } \\
\hline AGE & 38.5966 & 11.4593 & 16.0000 & 67.0000 & 1661 \\
\hline MALE & .5370 & .4988 & .0000 & 1.0000 & 1661 \\
\hline HIGHSCH & .5352 & .4989 & .0000 & 1.0000 & 1661 \\
\hline COLLEGE & .0686 & .2529 & .0000 & 1.0000 & 1661 \\
\hline CHILD18 & .3372 & .4729 & .0000 & 1.0000 & 1661 \\
\hline MARRIED & .4654 & .4990 & .0000 & 1.0000 & 1661 \\
\hline SOCBEN & .2444 & .4299 & .0000 & 1.0000 & 1661 \\
\hline DISABIL & .3113 & .4632 & .0000 & 1.0000 & 1661 \\
\hline VRBEN & .5099 & .5001 & .0000 & 1.0000 & 1661 \\
\hline INCOME & .8565 & .7485 & .0000 & 4.1110 & 1661 \\
\hline EXPER & 12.0692 & 7.8085 & .0000 & 26.0000 & 1661 \\
\hline SPOUSEINC & .7296 & 1.0274 & .0000 & 10.2000 & 1661 \\
\hline JOB_1 & .4967 & .5001 & .0000 & 1.0000 & 1661 \\
\hline DIAGNO & .1559 & .3629 & .0000 & 1.0000 & 1661 \\
\hline DIAGN1 & .4257 & .4946 & .0000 & 1.0000 & 1661 \\
\hline DIAGN2 & .2185 & .4134 & .0000 & 1.0000 & 1661 \\
\hline DIAGN4 & .0518 & .2216 & .0000 & 1.0000 & 1661 \\
\hline DIAGN5 & .0476 & .2129 & .0000 & 1.0000 & 1661 \\
\hline DIAGN6 & .1005 & .3008 & .0000 & 1.0000 & 1661 \\
\hline YEAR89 & .2487 & .4324 & .0000 & 1.0000 & 1661 \\
\hline YEAR90 & .2571 & .4372 & .0000 & 1.0000 & 1661 \\
\hline YEAR91 & .2179 & .4130 & .0000 & 1.0000 & 1661 \\
\hline YEAR92 & .1987 & .3991 & .0000 & 1.0000 & 1661 \\
\hline YEAR93 & .0777 & .2677 & .0000 & 1.0000 & 1661 \\
\hline
\end{tabular}


Table 3. Marginal effects. Multinomial Logit Model

\begin{tabular}{|c|c|c|c|}
\hline Variables & Non-Participation & Work related & Educational \\
\hline \multirow[t]{2}{*}{ Constant } & $-.2391 *$ & $.2267 *$ & .0124 \\
\hline & $(.0314)$ & $(.0351)$ & $(.0236)$ \\
\hline \multirow[t]{2}{*}{ AGE } & $.0020 * *$ & $.0038^{*}$ & $-.0059 *$ \\
\hline & $(.0008)$ & $(.0009)$ & $(.0007)$ \\
\hline \multirow[t]{2}{*}{ HIGHSCH } & $-.0435^{*}$ & -.0190 & $.0625^{*}$ \\
\hline & $(.0117)$ & $(.0133)$ & $(.0095)$ \\
\hline \multirow{2}{*}{ COLLEGE } & -.0070 & $-.1150 *$ & $.1220 *$ \\
\hline & $(.0234)$ & $(.0262)$ & $(.0155)$ \\
\hline \multirow[t]{2}{*}{ INCOME } & .0065 & $-.0483^{*}$ & $.0417 *$ \\
\hline & $(.0098)$ & $(.0109)$ & $(.0068)$ \\
\hline \multirow[t]{2}{*}{ SPOUSEINC } & .0017 & -.0111 & $.0094 * *$ \\
\hline & $(.0072)$ & $(.0080)$ & $(.0049)$ \\
\hline \multirow[t]{2}{*}{ VRBEN } & $-.0264 * *$ & $-.0595 *$ & $.0859 *$ \\
\hline & $(.0118)$ & $(.0129)$ & $(.0082)$ \\
\hline \multirow[t]{2}{*}{ MALE } & $-.0414 *$ & $.0855^{*}$ & $-.0441 *$ \\
\hline & $(.0133)$ & $(.0146)$ & $(.0092)$ \\
\hline \multirow[t]{2}{*}{ MARRIED } & $.0359 * *$ & -.0194 & -.0165 \\
\hline & $(.0156)$ & $(.0176)$ & $(.0118)$ \\
\hline \multirow[t]{2}{*}{ DISABIL } & $.1423^{*}$ & $-.0394 * *$ & $-.1029 *$ \\
\hline & $(.0138)$ & $(.0170)$ & $(.0135)$ \\
\hline \multirow[t]{2}{*}{ EXPER } & $.0030 * *$ & -.0022 & -.0008 \\
\hline & $(.0012)$ & $(.0014)$ & $(.0010)$ \\
\hline \multirow[t]{2}{*}{ JOB_1 } & $-.0275^{* *}$ & $.0375^{*}$ & .0100 \\
\hline & $(.0128)$ & $(.0142)$ & $(.0091)$ \\
\hline \multirow[t]{2}{*}{ SOCBEN } & .0198 & .0227 & $-.0425 *$ \\
\hline & $(.0142)$ & $(.0156)$ & $(.0105)$ \\
\hline \multirow{2}{*}{ CHILD18 } & -.0126 & -.0110 & $.0236^{* * *}$ \\
\hline & $(.0135)$ & $(.0152)$ & $(.0100)$ \\
\hline \multirow[t]{2}{*}{ DIAGN1 } & $.0919 *$ & $-.0893 *$ & -.0026 \\
\hline & $(.0164)$ & $(.0177)$ & $(.0111)$ \\
\hline \multirow{2}{*}{ DIAGN2 } & .0179 & $.0405^{* *}$ & $-.0584 *$ \\
\hline & $(.0176)$ & $(.0189)$ & $(.0126)$ \\
\hline \multirow[t]{2}{*}{ DIAGN4 } & $.0549 * *$ & -.0375 & -.0175 \\
\hline & $(.0272)$ & $(.0293)$ & $(.0181)$ \\
\hline \multirow[t]{2}{*}{ DIAGN5 } & $.0739 * *$ & $-.1217 *$ & $.0478 * *$ \\
\hline & $(.0292)$ & $(.0323)$ & $(.0198)$ \\
\hline \multirow[t]{2}{*}{ DIAGN6 } & $.0869^{*}$ & $-.1182 *$ & $.0312 * *$ \\
\hline & $(.0220)$ & $(.0239)$ & $(.0140)$ \\
\hline \multirow[t]{2}{*}{ YEAR90 } & $.0325^{* *}$ & -.0221 & -.0104 \\
\hline & $(.0155)$ & $(.0176)$ & $(.0118)$ \\
\hline \multirow[t]{2}{*}{ YEAR91 } & .0108 & -.0112 & .0004 \\
\hline & $(.0161)$ & $(.0181)$ & $(.0117)$ \\
\hline \multirow[t]{2}{*}{ YEAR92 } & .0128 & -.0030 & -.0098 \\
\hline & $(.0169)$ & $(.0191)$ & $(.0127)$ \\
\hline YEAR93 & $-.1731 *$ & $.1290^{*}$ & $.0440 * *$ \\
\hline & $(.0209)$ & $(.0215)$ & $(.0125)$ \\
\hline $\mathrm{N}=6653$ & & & \\
\hline$\chi^{2}=1135.04$ & & & \\
\hline $\mathrm{DF}=44$ & & & \\
\hline
\end{tabular}

* Significant at $1 \%$. ** Significant at $5 \%$. 


\section{REFERENCES}

Aakvik, A. (2001) Bounding a matching estimator: the case of a Norwegian training program, Oxford Bulletin of Economics and Statistics, 63(1), pp. 115-143.

Acemoglu, D. \& Pischke, J.S. (1998) Why do firms train? Theory and evidence, Quarterly Journal of Economics, 113(1), pp. 79-119.

Ashenfelter, O. (1978) Estimating the effect of training programs on earnings, The Review of Economics and Statistics, 6(1), pp. 47-57.

Barron, J.M. \& Berger, M.C. \& Black, D.A. (1999) Do workers pay for on-the-job training?, Journal of Human Resources, 34(2), pp. 235-252.

Bassi, L.J. (1984) Estimating the effect of training programs with non-random selection, Review of Economics and Statistics, 66(1), pp. 36-43.

Becker, G.S. (1962) Investment in human capital: a theoretical analysis, Journal of Political Economy, 70(Supplement), pp. 9-49.

Becker, G.S. (1964) Human Capital (New York: NBER).

Belman, D. \& Heywood, J.S. (1997) Sheepskin effects by cohort: implications of job matching in a signaling model, Oxford Economic Papers, 49(4), pp. 623-637.

Cohn, E. \& Kiker, B.F. \& Mendes de Oliveira, M. (1987) Further evidence on the screening hypothesis, Economics Letters, 25, pp. 289-294.

Chapman, P.G. (1993) The Economics of Training (LSE Handbooks in Economics, London, HarvesterWheatsheaf).

Domencich, T. \& McFadden, D. (1975) Urban Travel Demand (North-Holland: Amsterdam).

Elliott, R. F. (1991) Labor Economics (London, McGraw-Hill).

Gibbons, R. (1992) Game Theory for Applied Economists (Princeton University Press).

Hansen, H.-T. (1996) Hvem er på attføring og hva blir gjort? (SNF-rapport 32/96 (in Norwegian)).

Heckman, J.J. \& Robb, R. (1985) Alternative methods for evaluating the impact of interventions, in: Heckman J.J. \& Singer, B. (Eds.) Longitudinal Analysis of Labor Market Data (Cambridge: Cambridge University Press). 
Heckman, J.J. \& Hotz, V.J. \& Dabos, M. (1987) Do we need experimental data to evaluate the impact of manpower training on earnings?, Evaluation Review, 11(4), pp. 395-427.

Heckman, J.J. \& Hotz, V.J. (1989) Choosing among alternative nonexperimental methods for estimating the impact of social programs: the case of manpower training, Journal of the American Statistical Association, 84(408), pp. 862-874.

Heckman, J.J. \& Smith, J.A. (1996) Experimental and nonexperimental evaluation, in: Schmidt, G. \& O'Reilly, J. \& Schomann, K. (Eds.) International Handbook of Labour Market Policy and Evaluation (Cheltenham: Elgar).

Hillier, B. (1997) The Economics of Asymmetric Information (London: MacMillan Press Ltd).

Hungerford, T. \& Solon, G. (1987) Sheepskin effects in the returns to education, The Review of Economics and Statistics, 69, pp. 175-177.

Kroch, E.A. \& Sjoblom, K. (1994) Schooling as human capital or a signal: some evidence, The Journal of Human Resources, 21(1), pp.156-180.

Lang, K. (1994) Does the human-capital/educational-sorting debate matter for development policy?, American Economic Review, 84(1), pp. 353-358.

Loh, E.S. (1994) Employment probation as a sorting mechanism, Industrial and Labor Relations Review, 47(3), pp. 471-486.

McFadden, D. (1973) Conditional logit analysis of qualitative choice behaviour, in: Zarembka, P. (Ed.) Frontiers in Econometrics (Academic Press: New York).

McFadden, D. (1976) Quantal choice analysis: a survey, Annals of Economic and Social Measurement, 5(4), pp. 363-90.

McFadden, D. (1978) Modelling the choice of residential location", in: Karlqvist, L. \& Lundqvist, L. \& Snickars, F. \& Weibull, J. (Eds.) Spatial Interaction Theory and Planning Models (North-Holland, Amsterdam).

Moffitt, R. (1991) Program evaluation with nonexperimental data, Evaluation Review, 15(3), pp. 291-314.

OECD (1996) Assessing and Certifying Occupational Skills and Competences in Vocational Education and Training (Paris: OECD).

OECD (1998) Human Capital Investments: An International Comparison (Paris: OECD). 
Spence, A.M. (1973) Job market signaling, Quarterly Journal of Economics, 87(3), pp. 355-74.

Spence, A.M. (1974) Market Signaling: Informational Transfer in Hiring and Related Processes (Cambridge: Harvard University Press).

Weiss, A. (1995) Human capital vs. signalling explanations of wages, Journal of Economic Perspectives, 9(4), pp. 133-154. 